Int. J. Electrochem. Sci., 14 (2019) $6586-6602$

International Journal of

ELECTROCHEMICAL

SCIENCE

WWW.electrochemsci.org

\title{
Effect of Methoxypolyethylene Glycol on Trivalent Chromium Electrodeposition
}

\author{
Wenjuan Zhang ${ }^{1}$, Lei Shi ${ }^{1}$, Dongfang Niu ${ }^{1}$, Heng X $u^{2}$, Xinsheng Zhang ${ }^{1, *}$ and Shuozhen Hu ${ }^{1, *}$ \\ ${ }^{1}$ State Key Laboratory of Chemical Engineering, East China University of Science and Technology, \\ Shanghai, 200237, China \\ ${ }^{2}$ Collaborative Innovation Center for Petrochemical New Materials, Anqing, 246011, Anhui, China \\ *E-mail: shuozhen.hu@ecust.edu.cn, xszhang@ecust.edu.cn
}

doi: $10.20964 / 2019.07 .38$

Received: 18 March 2019 / Accepted: 6 May 2019 / Published: 10 June 2019

\begin{abstract}
The effect of methoxypolyethylene glycol (mPEG) on chromium electrodeposition from a mixture of 1butyl-3-methylimidazolium-bromide ([BMIM]Br) ionic liquid and water is studied. The addition of mPEG does not affect the two-step reduction process of $\mathrm{Cr}$ (III). With the presence of mPEG in the electrolyte, the diffusion coefficient decreases dramatically, and the resistance of the electrolyte and charge transfer increase, resulting in a reduced deposition rate and a smooth and crack-free coating surface. The hydrogen evolution reaction is suppressed, and more metallic $\mathrm{Cr}$ is deposited in the coating layer. Considering both the surface morphology and corrosion resistance, $80 \mathrm{mmol} \mathrm{L}^{-1} \mathrm{mPEG}$ is the optimum concentration for smooth and pinhole-free chromium electrodeposition in the mixture of [BMIM]Br ionic liquid and water.
\end{abstract}

Keywords: Trivalent chromium, Electrodeposition, 1-Butyl-3-methylimidazolium-bromide ionic liquid, Methoxypolyethylene glycol

\section{$\underline{\text { FULL TEXT }}$}

(C) 2019 The Authors. Published by ESG (www.electrochemsci.org). This article is an open access article distributed under the terms and conditions of the Creative Commons Attribution license (http://creativecommons.org/licenses/by/4.0/). 